\section{Commentary: A star shines brightest in the dark: The way surgeons work in the heart team}

\author{
Sung Jun Park, MD, and Joon Bum Kim, MD, PhD
}

In the September 2020 issue of the Journal, Cangut and Greason $^{1}$ reported a surgical repair of iatrogenic acute type A aortic dissection (AD) that had developed during transfemoral transcatheter aortic valve implantation (TAVI). The authors commendably saved a patient, who could have otherwise gone through a catastrophic course, with a prompt and smart surgical strategy. Under retrograde type A AD, which presumably occurred during the insertion of the delivery device, the authors first completed the deployment of TAVI and simply repaired the dissected aortic root using a felt-sandwich technique, leaving the TAVI valve remaining. There was a small entry tear at the proximal descending thoracic aorta, and ascending aorta replacement was performed as a rescue therapy, considering the frailty of patient.

$\mathrm{AD}$ is a well-known vascular complication of TAVI, albeit rare. Meanwhile, since most dissections are confined to vascular access and rarely extend to the thoracic level, acute type A AD is extremely rare, and only few reports are available. ${ }^{2}$ There may be 2 dominant clinical scenarios in which acute type A AD can occur. At first, antegrade type A AD can develop from the aortic valve annulus level during balloon aortic valvuloplasty before the valve implantation. ${ }^{3}$ Second, aortic intimal wall injuries during the insertion of delivering device can trigger ante/retrograde acute type $\mathrm{A} \mathrm{AD}$, as in the present case. ${ }^{4-6}$ The intimal injury can occur anywhere from the level of aortic arch

\footnotetext{
From the Department of Thoracic and Cardiovascular Surgery, Asan Medical Center, University of Ulsan College of Medicine, Seoul, South Korea.

Disclosures: The authors reported no conflicts of interest.

The Journal policy requires editors and reviewers to disclose conflicts of interest and to decline handling or reviewing manuscripts for which they may have a conflict of interest. The editors and reviewers of this article have no conflicts of interest.

Received for publication Aug 28, 2020; revisions received Aug 28, 2020; accepted for publication Aug 28, 2020; available ahead of print Sept 15, 2020.

Address for reprints: Joon Bum Kim, MD, PhD, Department of Thoracic and Cardiovascular Surgery, Asan Medical Center, University of Ulsan College of Medicine, 88, Olympic-Ro- 43-Gil, Songpa-Gu, Seoul, Korea 05505 (E-mail: jbkim1975@ amc.seoul.kr).

JTCVS Techniques 2020;4:83-4

2666-2507

Copyright (C) 2020 The Authors. Published by Elsevier Inc. on behalf of The American Association for Thoracic Surgery. This is an open access article under the CC BY-NCND license (http://creativecommons.org/licenses/by-nc-nd/4.0/).

https://doi.org/10.1016/j.xjtc.2020.08.058
}

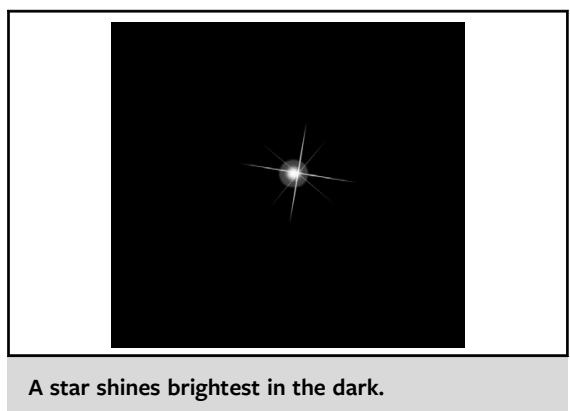

CENTRAL MESSAGE

latrogenic type A aortic dissec-

tion complicated during TAVI

procedure was successfully

treated by a heart team. Accu-

mulation of such experiences will

pave the way for the surgeons in

the heart team.

to ascending aorta, but it seems that retrograde type A dissection scarcely occurs from the vascular access site at the transfemoral setting. Prompt and accurate recognition for the underlying cause of $\mathrm{AD}$ will be paramount to rescue this chaotic and overwhelming complication.

Due to its rare presentation, literature reporting the outcomes of surgical management for iatrogenic acute type A AD developed during transfemoral TAVI is limited. Nevertheless, it has been perceived as a devastating complication when glancing the similar experiences in the cardiac or aortic surgery with operative mortality of $30 \%$ to $50 \%{ }^{7}$

It seems that the authors correctly recognized the cause of intraprocedural $\mathrm{AD}$, and the subsequent procedures were adequately performed without delay. The patient could have died if the TAVI device was retrieved instead of completion of the procedure. The rescue surgery was also performed as smartly as needed. It was the moment when the heart team brightly shined.

\section{References}

1. Cangut B, Greason KL. Treatment of iatrogenic acute aortic type A aortic dissection complicating transcatheter aortic valve insertion: a case report. J Thorac Cardiovasc Surg Tech. 2020;3C:68-9.

2. Walther T, Hamm CW, Schuler G, Berkowitsch A, Kötting J, Mangner N, et al. Perioperative results and complications in 15,964 transcatheter aortic valve replacements: prospective data from the GARY registry. J Am Coll Cardiol. 2015; 65:2173-80.

3. Ong SH, Mueller R, Gerckens U. Iatrogenic dissection of the ascending aorta during TAVI sealed with the CoreValve revalving prosthesis. Catheter Cardiovasc Interv. 2011;77:910-4. 
4. Kawajiri H, Pochettino A. Chronic type A aortic dissection after transcatheter aortic valve replacement. Ann Thorac Surg. 2020;109:e431-3.

5. Nagasawa A, Shirai S, Hanyu M, Arai Y, Kamioka N, Hayashi M. Descending aortic dissection injured by tip of the sheath during transcatheter aortic valve implantation. Cardiovasc Interv Ther. 2016;31: $122-7$
6. D’Ancona G, Kische S, Dissmann M, Pasic M, Mladenow A, Ince H. Transfemoral uncovered stent to treat iatrogenic type A dissection during transcatheter aortic valve implantation. Eur Heart J. 2015;36:187.

7. Shea NJ, Polanco AR, D'Angelo A, Bethancourt CN, Sanchez J, George I, et al Improving outcomes of iatrogenic type A aortic dissection during cardiac surgery Aorta (Stamford). 2019:7:115-20. 